\title{
NON-PROPORTIONAL HAZARDS WITH APPLICATION TO KIDNEY TRANSPLANT DATA
}

\author{
EMEL BAŞAR
}

\begin{abstract}
The Cox proportional hazards (PH) model is the popular method for modelling censored survival data. The fundamental assumption of the Cox $\mathrm{PH}$ model is the proportionality of hazards in which the hazard ratio is linear in the covariates. However this assumption may not hold in some survival studies. Therefore, different non-parametric regression methods have been proposed to estimate the hazard ratio as a function of time when the proportionality of hazards can not be assumed. In this study a piecewise model and a non-parametric regression spline model have been considered for the non-proportional hazards. The models have been illustrated with kidney transplant data..
\end{abstract}

\section{INTRODUCTION}

The Cox proportional hazards (PH) model introduced by Cox [4] has been widely used in analysis of survival data. The term proportional hazards refer to the fact that covariates have a multiplicative effect on the hazards and the ratio of the hazards for different individuals is constant over the time. This assumption may not be met in all censored survival data set. The impact of a covariate on hazards may change during the follow-up. Several tests have been proposed to check the proportional hazards hypothesis [14]. However, after having rejected the PH hypothesis, it is not obvious how to summarize the effect of a covariate [1].

The standard method for modelling the effect of a predictor that violates the $\mathrm{PH}$ assumption is to include a time dependent covariate, representing an interaction between the covariate and a parametric function of follow-up time and its shape represents the changes in hazard ratio during follow-up. Another method was proposed by Moreau et. al. [15]. They fitted a piecewise PH model. In that model, hazard ratio becomes a step function that is constant within each a priori determined time interval but varies between intervals. However, the resulting estimates

Received by the editors March 12, 2007; Rev. June 1, 2007; Accepted: June 17, 2007.

2000 Mathematics Subject Classification. Primary 62N01, 62G08; Secondary 62N02.

Key words and phrases. Cox regression, Proportional hazards, Regression splines, Survival analysis. 
are unsmooth and impact of the number of intervals is not obvious. In the 1990's several authors developed non-parametric methods for modeling time-dependent hazard ratio as a smooth flexible function of time [16].

Splines are a better tool for exploring nonlinear relationships and flexible statistical techniques. There are two classes of splines: regression splines and smoothing splines. Regression splines are piecewise polynomials joined at control points that are called knots. Linear splines constitute a set of connected line segments, which are continuous functions with discontinuous first derivative at the knots. Quadratic splines have continuous first derivatives, cubic splines continuous first and second derivatives. They are very attractive for non-parametric modeling; but, choosing the number of knots or the location of knots is arbitrary [19]. An alternative to the regression spline is the smoothing spline. The smoothing splines have knots located at every unique value of the continuous predictor variable, and include a penalty for overfitting. The smoothing splines have been used in generalized additive models [7].

A large number of works have been done on the regression spline methods and varying-coefficient models. Some of these studies among the others are: Sleeper and Harrington [18], Gray [9], Hastie and Tibshirani [11], Gray [10], Hess [12], Kooperberg et al. [13], Rosenberg [17], Abrahamowicz et al. [1], Cai and Sun [3].

In this study, testing of PH hypothesis based on the Grambsch-Therneau test [8] has been considered. Time-dependent model, piecewise PH model with two and three intervals, and regression splines model with four degrees of freedom have been considered for modelling non-proportionality. These models are illustrated with the kidney transplantation data.

\section{PROPORTIONAL HAZARDS MODEL}

In the Cox PH model, introduced by Cox [4], the hazard at time $t$ is define as:

$$
\lambda(t ; x)=\lambda_{0}(t) \exp \left(\sum_{i=1}^{p} \beta_{i} x_{i}\right)
$$

where, $\lambda(t ; x)$ is the hazard rate at time $t$ for individual with covariate vector

$x . \beta_{1}, \beta_{2}, \ldots, \beta_{p}$ are the unknown regression parameters called log hazard ratios and represent the effect of each covariate on the logarithm of the hazard. $\lambda_{0}$ is an unspecified non-negative function of time called baseline hazard. The model assumes that the hazard ratio between two subjects with fixed covariates is constant. When the assumption of proportionality does not hold, the Cox PH model may produce biased results and the alternative models have to be considered.

\section{PIECEWISE PROPORTIONAL HAZARDS MODEL}

The piecewise $\mathrm{PH}$ model incorporates non-proportional hazards in the Cox model by representing hazard ratio as a step function of time [15]. Hazard ratio is constant 
within each of $r$ pre-specified time intervals but varies between the intervals. Within the $i$-th interval $(j=1, \ldots, r)$, the hazard is expressed by:

$$
\lambda(t ; x)=\lambda_{0}(t) \exp \left(\sum_{i=1}^{p}\left(\beta_{i}+\gamma_{j i}\right) x_{i}\right)
$$

where $\gamma_{1 i}=0$. The $\log$ hazard ratio equals to $\beta_{i}$ in the first interval and $\left(\beta_{i}+\gamma_{j i}\right)$ in the subsequent intervals for $j=2, \ldots, r$. The $\mathrm{PH}$ model becomes a special case of the piecewise model [16]. In this study the piecewise analysis is limited with two and three intervals, because there are many failures on the beginning of the follow-up period.

\section{REGRESSION SPLINES MODEL}

A spline is a piecewise polynomial that has continuous derivatives at the points where pieces join. When a continuous covariate affects the log hazard in a smooth fashion, a spline function is natural choice for approximating the covariate transformation [18].

The non-parametric spline model is defined as:

$$
\lambda(t ; x)=\lambda_{0}(t) \exp \left(\sum_{i=1}^{p} \beta_{i}(t) x_{i}\right)
$$

where $x=\left(x_{1}, \ldots, x_{p}\right)$ is a vector of $p$ covariates, $\lambda_{0}(t)$ is an unspecified baseline hazard function corresponding to $x=0$, and $\beta_{i}(t)$ is the logarithm of the hazard ratio at time $t$ corresponding to a unit increase in covariate $x_{i}$. This model is generalized PH model with the constant $\log$ hazard ratios $\beta_{i}$ are replaced by estimable functions of time $\beta_{i}(t)$. The effects of some covariates may still be constant. It is assumed that non-constant functions $\beta_{i}(t)$ lie in a pre-chosen polynomial regression spline space. Regression splines are smooth piecewise polynomials with pieces that join at knots. The degrees of polynomial pieces and the number and location of knots may vary. $k$ is the spline order (or polynomial degree $k-1$ ) and $m$ is the number of knots. A space of regression splines is linear, and its dimension is $m+k$. For each $i$ the following expression can be written:

$$
\beta_{i}(t)=\sum_{j=1}^{r_{i}} \alpha_{i j} g_{i j}(t)
$$

where $r_{i}$ is the dimension of regression spline space for $i$-th covariate and $\alpha_{i j}$ is the regression parameter and $g_{i j}(t)$ are basis function for this space. A useful basis for this linear space is given by de Boor [5] and called B-splines. B-spline base functions are numerically well-conditioned. Model (3) can be rewritten as:

$$
\lambda(t ; x)=\lambda_{0}(t) \exp \left(\sum_{i=1}^{p} \sum_{j=1}^{r_{i}} \alpha_{i j} y_{i j}(t)\right)
$$


where $y_{i j}(t)=g_{i j}(t) x_{i}[1]$.

De Boor [5] gave an algorithm to compute B-splines of any degree from B-splines of lower degree. Because a zero-degree B-spline is a constant on one interval between two knots, it is simple to compute B-splines of any degree. The choice of knots has been a subject much research, too many knots lead to overfitting of the data, too few knots lead to underfitting [6].

The degree of freedom for the fit is given by the number of basis functions, equal to the number of fitted regression coefficients. For regression splines, the degree of freedom equals the number of knots plus 1 . One degree of freedom corresponds a straight line. Increasing the degrees of freedom corresponds to more complicated curves [19].

\section{APPLICATION TO KIDNEY TRANSPLANT PATIENTS}

The data has been collected from register of patients at Başkent University Hospital and it consists of survival data of 93 patients who were operated kidney transplantation [2]. The beginning of the lifetimes is defined as the operation time and the end point of the lifetimes are the rejection of kidney or the death of the patients. The follow-up time is 35 months and the eighteen failures have been observed during the study period. Various covariates have been collected and only four of them included in this study. These covariates are patient age, donor age, disease duration and sex.

First, the Cox PH model is fitted to the data. The results of the univariate and multivariable Cox PH models are summarized in Table 1, giving the estimators of hazard ratios for each covariate and their confidence intervals and its $p$-value from the likelihood ratio test. Donor age is the only covariate that shows a statistically significant impact on the survival at the level of $\alpha=0.05$ in the context of both the univariate and multivariable $\mathrm{Cox} \mathrm{PH}$ models.

Table 1-Univariate and multivariable Cox proportional hazards analysis

\begin{tabular}{lcccccccc}
\hline & \multicolumn{3}{c}{ Univariate analysis } & \multicolumn{3}{c}{ Multivariable analysis } \\
\hline Covariates & $\begin{array}{c}\text { Hazard } \\
\text { ratio }\end{array}$ & \multicolumn{2}{c}{$\begin{array}{c}\text { 95\% conf. } \\
\text { intervals }\end{array}$} & $p$-value & $\begin{array}{c}\text { Hazard } \\
\text { ratio }\end{array}$ & $\begin{array}{c}95 \% \text { conf. } \\
\text { intervals }\end{array}$ & $p$-value \\
\hline Patient age & 0,998 & 0,957 & 1,042 & 0,944 & 0,999 & 0,952 & 1,047 & 0,950 \\
Donor age & 1,046 & 1,005 & 1,089 & 0,028 & 1,045 & 1,003 & 1,089 & 0,037 \\
Disease duration & 1,088 & 0,984 & 1,204 & 0,999 & 1,074 & 0,770 & 1,190 & 0,170 \\
Sex & 0,821 & 0,292 & 2,302 & 0,710 & 0,848 & 0,288 & 2,499 & 0,176 \\
\hline
\end{tabular}

The proportional hazards model hypotheses are tested for each covariate based on scaled Schonfeld residuals [19]. In Figure 1 the plot of scale residuals are given against ordered time along with spline smooth together $90 \%$ confidence intervals. The Grambsch-Therneau test has $p$-value $=0.041$ for donor age and this provides the evidence that the covariate donor age violates the $\mathrm{PH}$ assumption at the level 
of $\alpha=0.05$. The impact of the donor age score clearly changes with time and this time-varying effect can be seen in Figure 1. The other covariates do not show a timevarying pattern. The $p$-values for covariates patient age, disease duration, and sex are respectively $0.478,0.584$, and 0.567 . When the assumption of proportionality does not hold, alternative models have to be considered.

For categorical covariates apparent non-proportionality can be handled by stratification, but this is impossible for continuous covariates. To model non-proportional hazards, an interaction term between the covariates and a pre-specified parametric function is included in the Cox PH model [4]. Several functions are considered in this study. These are $f(t)=t, f(t)=\ln t$ and $f(t)=\sqrt{t}$.

Table 2 demonstrates that some conclusions depend on the number of intervals, considered function and regression splines model. For patient age and disease duration, non-proportionality of hazards is significant with two and three intervals. First two time-dependent models suggested that $\mathrm{PH}$ hypothesis is rejected for patient age, donor age and disease duration. For splines model, PH assumption is statistically significant for all the covariates. In the piecewise model with two intervals and splines model $p$-value could not compute for sex.
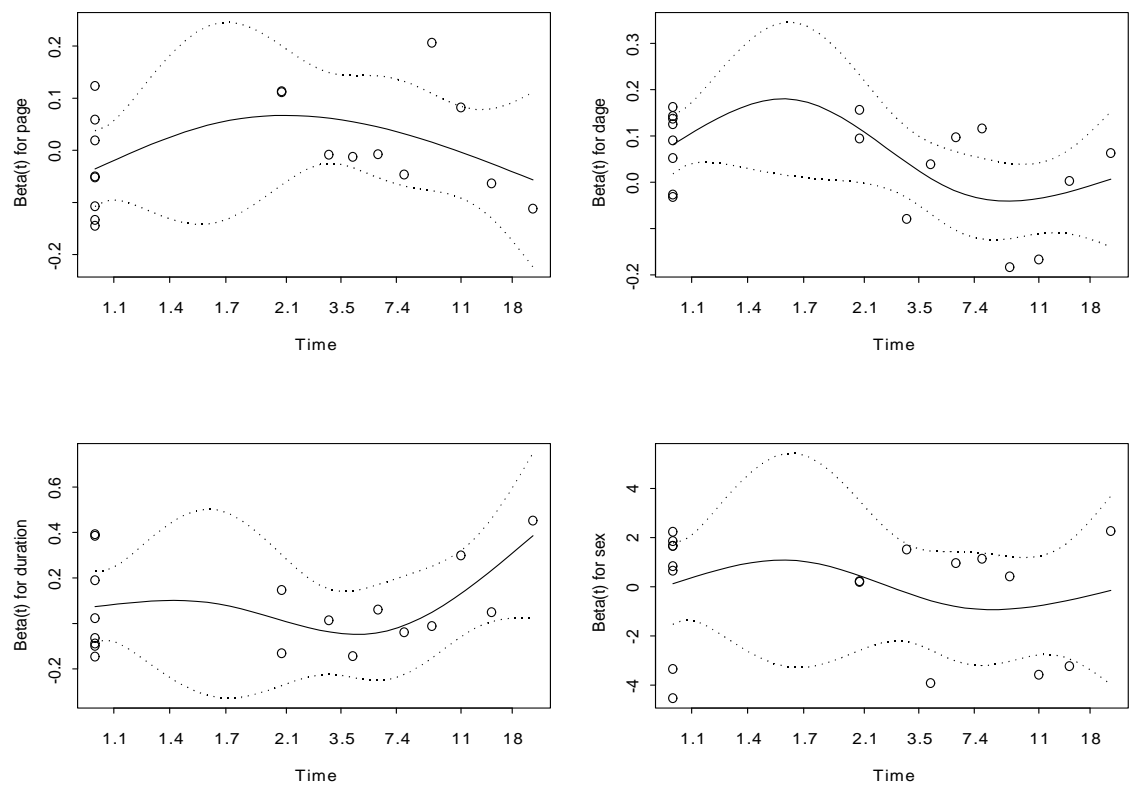

Figure 1- Test of proportional hazards with a spline smooth for all covariates. 
Table 2- Testing the proportional hazards hypothesis $p$-values based on multivariable model

\begin{tabular}{lcccccc}
\hline & \multicolumn{2}{c}{ Piecewise model } & \multicolumn{3}{c}{ Time-dependent model } & Splines \\
\cline { 2 - 6 } Covariate & Two intervals & Three intervals & $t$ & $\ln t$ & $\sqrt{t}$ & \\
\hline Patient age & 0,004 & 0,015 & 0,002 & 0,000 & 0,006 & 0,707 \\
Donor age & 0,194 & 0,226 & 0,036 & 0,001 & 0,020 & 0,297 \\
Disease duration & 0,002 & 0,001 & 0,022 & 0,033 & 0,167 & 0,624 \\
Sex & - & 0,216 & 0,375 & 0,022 & 0,234 & - \\
\hline
\end{tabular}

Comparisons of goodness-of-fit of different univariate models by using the Akaike Information Criterion (AIC) are given in the Table 3. Lower AIC values indicate better fit. For each covariate, the best fitting model is identified by '* '. The numbers in the same row show the difference in AIC values between respective models and the best model. AIC values in Table 3 show that time-dependent models fit much better than the other models.

Table 3- Goodness-of-fit of univariate models with differences in AIC values

\begin{tabular}{lcccccc}
\hline & \multicolumn{4}{c}{ Piecewise model } & \multicolumn{4}{c}{ Time-dependent model } & Splines \\
\cline { 2 - 6 } Covariate & Two intervals & Three intervals & $t$ & $\ln t$ & $\sqrt{t}$ & \\
\hline Patient age & 30,69 & 27,92 & $*$ & 7,97 & 2,30 & 69,94 \\
Donor age & 33,96 & 60,67 & $*$ & 4,98 & 0,30 & 77,33 \\
Disease duration & 37,34 & $*$ & 28,37 & 33,29 & 30,50 & 60,03 \\
Sex & - & 14,18 & 6,59 & $*$ & 1,63 & - \\
\hline
\end{tabular}

Table 4 shows the results of testing of the proportionality for multivariable modelling. In the multivariable analysis three homogeneous versions of time-dependent models were specified as a priori. Each of these models represented time-dependent effects of all covariates by one of the three functions that are $f(t)=t, f(t)=\ln t$, $f(t)=\sqrt{t}$. The optimal model is defined as a posteriori and the effect of each factor was represented by the function that fitted best in the univariate analysis. The first row of Table 4 shows AIC values, as expected, the optimal model fits the data better than the three other time-dependent models. The spline model has the biggest $\mathrm{AIC}$ value. 
Table 4- Testing the proportional hazards model hypothesis for multivariable models

\begin{tabular}{lccccc}
\hline & $t$ & $\ln t$ & $\sqrt{t}$ & Optimal & Splines \\
\cline { 2 - 6 } AIC & 78,1 & 86,9 & 80,3 & 77,8 & 164,7 \\
Overall test of PH & 86,0 & 77,1 & 83,7 & 86,2 & 7,30 \\
$p$-value & $<0,00$ & $<0,00$ & $<0,00$ & $<0,00$ & 0,504 \\
\hline
\end{tabular}

Table 5 represents the hazard ratio estimates for donor age with different models. The proportional hazards assumption fails to hold only the donor age. Because of this reason, in these models four covariates are included and only the hazard ratio of donor age has time-dependent effect. All models are statistically significant and the hazard ratios are decreased over time except the splines model.

Table 5- Hazard ratio estimates for donor age

\begin{tabular}{lccccc}
\hline \multicolumn{1}{c}{$\begin{array}{c}\text { Covariate } \\
\text { and models }\end{array}$} & \multicolumn{5}{c}{ Time } \\
\cline { 2 - 6 } $\begin{array}{l}\text { Donor age } \\
\text { Cox PH }\end{array}$ & 1,045 & 1,045 & 1,045 & 1,045 & 1,045 \\
$\begin{array}{l}\text { Piecewise } \\
\text { Two intervals }\end{array}$ & 0,961 & 0,961 & 1,072 & 1,072 & 1,072 \\
$\begin{array}{c}\text { Three intervals } \\
\text { Time-dependent }\end{array}$ & 0,948 & 1,111 & 1,055 & 1,055 & 1,055 \\
$\quad t$ & 1,124 & 1,106 & 1,036 & 0,939 & 0,851 \\
$\quad \ln t$ & 1,152 & 1,050 & 0,999 & 0,946 & 0,916 \\
$\quad \sqrt{t}$ & 1,139 & 1,103 & 1,017 & 0,939 & 0,883 \\
Splines & 0,587 & 0,843 & 0,105 & 10.737 & 10.737 \\
\hline
\end{tabular}

\section{DISCUSSIONS}

In this study a kidney transplantation data is used to assess the performance of different models in univariate and multivariable analysis. The piecewise $\mathrm{PH}$ models, Cox PH model with time-dependent covariates and splines model are considered for this purpose. The results of piecewise models depend on the arbitrary number of time intervals and are difficult to implement in multivariable modelling as mentioned in [16]. In the Cox model with time-dependent covariates the selection of parametric function is very important. Restricting the analysis to a single a priori selected parametric function may result biased estimates. The optimal model is defined by estimating different parametric function and selecting the best fitting model. The different parametric estimates fit data equally well and also induces overestimation bias. The regression spline model is flexible modelling for non-proportionality of the hazard ratio. But surprisingly, spline model did not fit the data well. Probably that is because the data is collected in relatively short-term study and most of the failures are observed at the beginning of the study. 


\section{ÖZET}

Cox orantılı hazard $(\mathrm{OH})$ modeli durdurulmuş yaşam sürdürme verisini modellemek üzere en çok kullanılan yöntemdir. Cox $\mathrm{OH}$ modelinin temel varsayımı hazardın orantılı olmasıdır. Hazard oranı ise eşdeğişkenler üzerinde doğrusaldır. Bazı yaşam sürdürme çalışmalarında bu varsayım sağlanamayabilir. Hazardın orantılı olmasının varsayılamadığı durumda, hazard oranını zamanın bir fonksiyonu olarak tahmin etmek üzere farklı parametrik olmayan regresyon yöntemleri önerilmiştir.

$\mathrm{Bu}$ çalışmada orantılı olmayan hazard için, parçalı orantılı hazard modeli ve parametrik olmayan regresyon spline modeli dikkate alınmış ve modeller böbrek nakli verisine uygulanmıştır.

\section{REFERENCES}

[1] Abrahamowicz, M., MacKenzie, T., Esdaile, J. M., Time-dependent hazard ratio: modelling and hypothesis testing with application in lupus nephritis, Journal of the American Statistical Association, 91(1996), 1432-1439.

[2] Başar, E., Applications of some statistical technique used in life table analysis to the kidney transplantation data, Unpublished Ph. D., thesis, Science Institute of Hacettepe University. 1993.

[3] Cai, Z., Sun, Y., Local linear estimation for time-dependent coefficients in Cox's regression models, Scandinavian Journal of Statistics, 30(2003), 93-111.

[4] Cox, D. R. Regression models and life tables, Journal of the Royal Statistical Society, Ser. B, 34(1972), 187-220.

[5] De Boor, C., A Practical Guide to Splines, Springer, New York, 1978.

[6] Eilers, P. H. C., Marx, B. D., Flexible smoothing with B-splines and penalties, Statistical Science, 89(1996), 89-121.

[7] Eisen, A. E., Agalliu, I., Thurston, S. W., Coull, B. A., Checkoway, H., Smoothing in occupational cohort studies: an illustration based on penalised splines, Occupational and Environmental Medicine, 61(2004), 854-860.

[8] Grambsch, P. M., Therneau T. M., Proportional hazards test and diagnostics based on weight residuals, Biometrika, 81(1994), 515-526.

[9] Gray, R. J., Flexible methods for analyzing survival data using splines, with applications to breast cancer prognosis, Journal of the American Statistical Association, 87(1992), 942-951.

[10] Gray, R. J., Spline-based test in survival analysis, Biometrcs, 50(1994), 640-652.

[11] Hastie, T., Tibshirani, R., Varying-coefficient models, Journal of the Royal Statistical Society, Ser. B, 55(1993), 757-796.

[12] Hess, K. R., Assessing time-by-covariate interactions in proportional hazards regression models using cubic spline functions, Statistics in Medicine, 13(1994), 1045-1062.

[13] Kooperberg, C., Stone, C. J., Truong, Y. K., Hazards regression, Journal of the American Statistical Association, 90(1995), 78-94.

[14] Lin, D. Y., Wei, L. J., Goodness-of-fit test for the general Cox regression model, Statistica Sinica, 1(1991), 1-17.

[15] Moreau, T., O'Quigley, J., Mesbah, M. A., A global goodness-of-fit statistic for the proportional hazards model, Applied Statistics, 34(1985), 212-218. 
NON-PROPORTIONAL HAZARDS WITH APPLICATION TO KIDNEY TRANSPLANT DATA 63

[16] Quantin, C., Abrahamowicz, M., Moreau, T., Bartlett, G., MacKenzie, T., Tazi, M. A., Lalonde, L., Faivre, J., Variation over time of the effects of prognostic factors in a populationbased study of colon cancer: comparison of statistical models, American Journal of Epidemiology, 150(1999), 1188-1200.

[17] Rosenberg, P. S., Hazard function estimation using B-splines, Biometrics, 51(1995), 874-887.

[18] Sleeper, A. L., Harrington, D. P., Regression splines in the Cox model with application to covariate effects in liver disease, Journal of the American Statistical Association, 85(1990), 941-949.

[19] Therneau, T. M., Grambsch, P. M., Modelling Survival Data: Extending the Cox Model, Springer, New York, 2000.

Current address: Gazi Üni. Fen-Edebiyat Fak., İstatistik Bölümü, 06500, Teknikokullar, Ankara, Türkiye

E-mail address: ebasar@gazi.edu.tr 